\title{
Oral Cancer Awareness and Knowledge in the City of Valongo, Portugal
}

\author{
Luís Silva Monteiro, ${ }^{1,2}$ Filomena Salazar, ${ }^{1}$ Júlio Pacheco, $^{1}$ and Saman Warnakulasuriya ${ }^{3}$ \\ ${ }^{1}$ Medicine and Oral Surgery Department, Dental Sciences Group, Health Sciences Research Centre, Instituto Superior de Ciências da \\ Saúde Norte, Rua Central de Gandra 1317, Paredes, 4585-116 Gandra, Portugal \\ ${ }^{2}$ Stomatology Department, Centro Hospitalar de São João, Polo de Valongo, 4440-563 Valongo, Portugal \\ ${ }^{3}$ Oral Medicine, Department of Clinical and Diagnostic Sciences and WHO Collaborating Centre for Oral Cancer, \\ King's College London Dental Institute, London SE5 9RW, UK
}

Correspondence should be addressed to Luís Silva Monteiro, lmonteiro.md@gmail.com

Received 16 May 2012; Accepted 20 June 2012

Academic Editor: Stephen Richmond

Copyright (C) 2012 Luís Silva Monteiro et al. This is an open access article distributed under the Creative Commons Attribution License, which permits unrestricted use, distribution, and reproduction in any medium, provided the original work is properly cited.

\begin{abstract}
We conducted a questionnaire survey among 602 subjects in order to analyze the awareness and knowledge on oral cancer among residents of the city of Valongo in Portugal. The cancer that most subjects were aware of was breast cancer (99\%). Oral cancer was the least mentioned cancer (68.6\%). There was awareness of the relationship between oral cancer and smoking among $89.5 \%$ subjects, but less of the association with alcohol misuse (63.3\%). Nonhealing mouth ulcers were identified as a sign or symptom of oral cancer by $90.0 \%$ and red or white patch by only $52.8 \%$ subjects. Whereas $94.5 \%$ agreed that early detection could improve the treatment outcome, a disheartening $28.1 \%$ believed that whether a person developed an oral cancer or not is a matter of luck and therefore is unavoidable. Surprisingly only $1.7 \%$ were ever submitted to or had knowledge of receiving a consultation regarding oral cancer. In conclusion, this survey demonstrates a general lack of awareness and knowledge on oral cancer in a population of Valongo. An oral health promotion strategy should involve elements of basic education on oral cancer for this population, and regular oral cancer screenings should be implemented in Valongo.
\end{abstract}

\section{Introduction}

Oral cancer is a major public health problem worldwide [1]. Oral and pharyngeal cancers grouped together are the sixth most common cancers in the world. The most recent estimated world incidence of oral cancer is around 263,861 new cases for the year of 2008. In Portugal in the same year, oral cancer was the 6th most frequent cancer in males, with 777 new cases (age-standardized incidence of 9.9/100,000 habitants) and 248 new cases among females (age-standardized incidence of 2.1/100,000 habitants) [2].

Almost $90 \%$ of oral cancers are squamous cell carcinomas [3]. Smoking, alcohol use, smokeless tobacco products, and HPV infections are the major risk factors, with an attributable risk of oral cancer due to both tobacco and alcohol of $80 \%$ [4].
Despite recent advances in the detection and treatment of cancer, visual accessibility of the oral mucosa, and the scientific knowledge on cancer risk factors, oral cancer carries a low survival rate (near 50\%) [5]. Earlier diagnosis greatly increases patient's chances of survival as the mouth is very accessible for a clinical or self-examination [6]. However, oral cancer is still frequently diagnosed in advanced stages. One of the main reasons may be the lack of information about the causes and knowledge of signs and symptoms of oral cancer among the population. Moreover, most of oral cancers are preventable if people know which risk factors they must control or eliminate. In Portugal, a study on oral cancer awareness and knowledge has not been performed.

The purpose of this study was to examine the awareness and knowledge of oral cancer in a hospital population of the city of Valongo in Portugal which could eventually aid in the planning of appropriate health promotion. 


\section{Study Population and Methods}

We conducted a cross-sectional study to assess the awareness and knowledge of oral cancer including its risk factors, signs and symptoms, and beliefs in a population attending to the Hospital of Nossa Senhora da Conceição of Valongo (HNSCV), in the north of Portugal. Face-to-face interviews with patients over the age of 18 were conducted by previously trained and calibrated interviewers, between the 10th of January and the 4th of April, 2011. The authorization and ethical approval were obtained from the HNSCV. The consented individuals were interviewed consecutively in the order of their arrival to the hospital, following their consent to the program. Of the 631 subjects invited to participate in the survey, 29 declined or abandoned the inquiry.

The questionnaire used (available as a web link and on request from the corresponding author) was based on similar previous works $[6,7]$. However, we adapted some questions to the Portuguese population. A pilot survey of 30 subjects was conducted and then some questions were modified.

The inquiry started with a standardized presentation of the interviewer as a student or a volunteer at HNSCV undertaking a study on cancer information (initially without mentioning words like oral cancer, mouth, or dentist). The questionnaire with 26 questions was divided in three parts: (1) a section on sociodemographic aspects; (2) a main questionnaire with questions on oral cancer awareness and knowledge and cancer beliefs; (3) the concluding section with information on lifestyle habits on smoking, alcohol consumption, fruit and vegetable intake, dentist visits, and oral hygiene habits (i.e., toothbrushing frequency). To assess oral cancer awareness, we asked "Of the following cancers which ones do you know of or have heard of?" listing a number of cancers including oral cancer. Then we asked "Have you heard about oral cancer screening? Have you had your mouth examined as a part of oral cancer detection?". Response categories for these questions were "yes," "no," or "don't know". Knowledge on oral cancer was assessed by prompted questions relative to oral cancer's frequency in different age groups $(0-17,18-24,25-44$, over 45-year old, do not know), gender (male, female), frequently affected location in mouth (gum, palate, tongue, floor of the mouth, cheek, do not know), world incidence (oral cancer is within the ten most common cancers in the world (yes, no, do not know), oral cancer deaths ( $<24 \%, 50 \%,>75 \%$, do not know), signs and symptoms, and causes by listing a number of items on these topics. We evaluated some individual oral cancer beliefs using three questions: "Getting oral cancer is a matter of luck and we cannot do anything to prevent this?", "The early discovery of this cancer can increase the success of your treatment", "Do you think we can change our lives to reduce the risk of cancer of the mouth?". Response categories for these 3 questions were "agree," "disagree," or "don't know."

Subjects who smoked cigarettes (or equivalents) at the rate of 20 or more per day were considered heavy smokers. Those who drank more than 14 units of alcohol per week (females) and more than 21 units per week (males) were considered as heavy drinkers [8]. The daily intake of vegetables and fresh fruits were categorized as consuming either five portions or more per day, or not [9]. The questionnaire is available on request from the authors.

2.1. Statistics. Each questionnaire was coded and entered into a Microsoft Excel database. To assess the reliability of interview data, completed interviews were subjected to a $10 \%$ field check by a process of reinterviews. The results were expressed in absolute and relative frequencies. The relationship between demographic and personal habits versus cancer awareness, cancer knowledge, and cancer beliefs were analyzed by chi-square test. Differences were considered statistically significant at $P<0.05$.

\section{Results}

Of the 602 individuals participating in the inquiry 381 $(63.3 \%)$ were females and $221(36.7 \%)$ were males. The mean age was 48.38 years $(S D \pm 15.2)$, in the age range of 18 and 86 years. Five hundred and ninety-nine were White Caucasians (99.5\%). Other demographic characteristics of the respondents are showed in Table 1.

Breast cancer was the cancer that most subjects were aware of (99\%) followed by lung cancer $(96.3 \%)$ and prostate cancer $(95.2 \%)$. Oral cancer was the least heard type of cancer $(68.6 \%)$ (Table 2$)$. Individuals with better oral hygiene habits were more aware of oral cancer $(n=375 ; 70.5 \%)$ than individuals with less frequent oral hygiene $(n=38 ; 54.3 \%)$. Also, individuals reporting visits to the dentist more than once a year were more aware of oral cancer $(n=195 ; 74.1 \%)$ than less frequent attenders $(n=218 ; 64.3 \%)(P=0.010)$.

Only $120(19.9 \%)$ individuals had heard of oral cancer screening. Ten $(1.7 \%)$ have had a mouth examination as part of oral cancer screening.

When asked which was the cancer most easier to detect (by health professionals), 90 (15\%) mentioned lung cancer, $339(56.3 \%)$ breast cancer, $15(2.5 \%)$ colon cancer, $42(7 \%)$ oral cancer, and $10(1.7 \%)$ pancreatic cancer. The remaining $106(17.6 \%)$ could not answer this question.

Only 131 (21.8\%) individuals mentioned that oral cancer affected more males than females. Twenty-eight $(4.7 \%)$ individuals answered that it affected more females, 369 $(61.3 \%)$ that it affects both sexes equally, and $74(12.3 \%)$ did not answer.

Most subjects $(n=461 ; 76.6 \%)$ did not know that head and neck cancer is within the 10 most frequent cancers in the world. When we asked the age group with the highest incidence of oral cancer, $12(2 \%)$ responded $0-18$ years, 28 (4.7\%) responded 18-25 years, 146 (24.3\%) 25-44 years, and $260(43.2 \%)$ said that it was more frequent in people 45 years or older. 156 (25.9\%) individuals reported they do not know the correct answer.

The location of the mouth most referred to as likely to develop oral cancer was the tongue $(n=204 ; 33.9 \%)$, followed by gums $(n=133 ; 22.1 \%)$, palate $(n=61 ; 10.1 \%)$, floor of the mouth $(n=29 ; 4.8 \%)$, and cheek mucosa $(n=28$; 4.7\%). Again 147 (24.4\%) individuals reported they do not know the correct answer. 
TABLE 1: Sociodemographic characteristics and their relations with some awareness and knowledge variables.

\begin{tabular}{|c|c|c|c|c|c|c|c|c|}
\hline Variables & $n$ & $\begin{array}{c}\text { Oral cancer } \\
\text { awareness } \\
(n=413 ; \\
68.6 \%)\end{array}$ & $\begin{array}{c}\text { Oral cancer } \\
\text { screening } \\
(n=120 \\
19.9 \%)\end{array}$ & $\begin{array}{c}\text { Tobacco as } \\
\text { risk factor } \\
(n=539 ; \\
89.5 \%)\end{array}$ & $\begin{array}{c}\text { Alcohol as } \\
\text { risk factor } \\
(n=381 ; \\
63.2 \%)\end{array}$ & $\begin{array}{l}\text { Ulcer as sign } \\
\qquad \begin{array}{c}n=542 ; \\
90 \%)\end{array}\end{array}$ & $\begin{array}{c}\text { Red/white } \\
\text { patch as sign } \\
(n=318 \\
52.8 \%)\end{array}$ & $\begin{array}{c}\text { Swelling as } \\
\text { sign } \\
(n=541 ; \\
89.9 \%)\end{array}$ \\
\hline \multicolumn{9}{|l|}{ Gender } \\
\hline Male & 221 & $143(64.7)$ & $48(21.7)$ & $206(93.2)$ & $145(65.6)$ & $193(87.3)$ & $112(50.7)$ & $191(86.4)$ \\
\hline Female & 381 & $270(70.9)$ & $72(18.9)$ & $333(87.4)$ & $236(61.9)$ & $349(91.6)$ & $206(54)$ & $350(91.9)$ \\
\hline$P$ & & 0.116 & 0.404 & 0.080 & 0.108 & 0.225 & 0.139 & 0.096 \\
\hline \multicolumn{9}{|l|}{ Age } \\
\hline$<49$ years & 298 & $198(66.4)$ & $52(17.4)$ & 274 (91.9) & $186(62.4)$ & $266(89.2)$ & $148(49.7)$ & $269(90.3)$ \\
\hline$\geq 49$ years & 304 & $215(70.7)$ & $68(22.4)$ & $265(87.2)$ & $195(64.1)$ & $276(90.8)$ & $170(55.9)$ & $272(89.5)$ \\
\hline$P$ & & 0.258 & 0.131 & 0.117 & 0.275 & 0.050 & 0.305 & 0.518 \\
\hline \multicolumn{9}{|l|}{ Professional class } \\
\hline $\mathrm{I} / \mathrm{II}$ & 56 & $43(76.8)$ & $13(23.2)$ & $52(92.9)$ & $30(53.6)$ & $51(91.1)$ & $35(62.5)$ & $53(94.6)$ \\
\hline III & 51 & $34(66.6)$ & $11(21.6)$ & $47(92.2)$ & $31(60.8)$ & $47(92)$ & $26(50.9)$ & $48(94.1)$ \\
\hline IV & 188 & $124(65.9)$ & $30(15.9)$ & $167(88.8)$ & $119(63.3)$ & $166(88.3)$ & $97(51.6)$ & $170(90.4)$ \\
\hline $\mathrm{V}$ & 307 & $212(69.1)$ & $66(21.5)$ & $273(88.9)$ & $201(65.4)$ & $278(90.6)$ & $160(52.1)$ & $270(87.9)$ \\
\hline$P$ & & 0.481 & 0.424 & 0.358 & 0.385 & 0.722 & 0.741 & 0.375 \\
\hline \multicolumn{9}{|l|}{ Marital status } \\
\hline Single & 112 & $76(67.8)$ & $20(17.9)$ & $110(98.2)$ & $75(66.9)$ & $100(89.3)$ & $56(50)$ & $103(92)$ \\
\hline Married & 402 & $275(68.4)$ & $77(19.2)$ & $355(88.3)$ & $256(63.7)$ & $361(89.9)$ & $216(53.7)$ & $362(90)$ \\
\hline $\begin{array}{l}\text { Widow/divorced/ } \\
\text { separated }\end{array}$ & 88 & $62(70.5)$ & $23(26.1)$ & $74(84)$ & $50(56.8)$ & $81(92)$ & $46(52.3)$ & $76(86.4)$ \\
\hline$P$ & & 0.916 & 0.276 & 0.014 & 0.177 & 0.290 & 0.672 & 0.479 \\
\hline \multicolumn{9}{|l|}{ Education } \\
\hline Without & 50 & $34(68)$ & $10(20)$ & $46(92)$ & $32(64)$ & $39(78)$ & $23(46)$ & $39(78)$ \\
\hline Primary school & 429 & $286(66.6)$ & $86(20)$ & $378(88.1)$ & $279(65)$ & $386(89.9)$ & $219(51)$ & $386(89.9)$ \\
\hline High-school & 81 & $58(71.6)$ & $15(18.5)$ & $74(91.4)$ & $49(60.5)$ & $77(54.3)$ & $49(60.4)$ & $75(92.6)$ \\
\hline $\begin{array}{l}\text { Technic- } \\
\text { vocation/university }\end{array}$ & 42 & $35(83.3)$ & $9(21.4)$ & $41(97.6)$ & $21(50)$ & $40(95.2)$ & $27(64.3)$ & $41(97.8)$ \\
\hline$P$ & & 0.149 & 0.983 & 0.271 & 0.083 & 0.054 & 0.336 & $<0.001$ \\
\hline \multicolumn{9}{|l|}{ Smoking } \\
\hline Nonsmoker & 367 & $258(70.3)$ & $77(21)$ & $319(86.9)$ & $221(60.2)$ & $330(90)$ & $203(55.3)$ & $328(89.4)$ \\
\hline Smoker & 141 & $93(65.9)$ & $30(21.3)$ & $135(95.7)$ & $94(66.7)$ & $126(89.4)$ & $61(43.3)$ & $131(92.9)$ \\
\hline Ex-smoker & 94 & $62(68)$ & $13(13.8)$ & $85(90.4)$ & $66(70.2)$ & $86(91.5)$ & $54(57.4)$ & $82(87.2)$ \\
\hline$P$ & & 0.534 & 0.272 & 0.048 & 0.126 & 0.060 & 0.088 & 0.077 \\
\hline \multicolumn{9}{|l|}{ Heavy smoking } \\
\hline No & 517 & $359(69.4)$ & $107(20.7)$ & $460(88.9)$ & $323(62.5)$ & $464(89.7)$ & $276(53.4)$ & $465(89.3)$ \\
\hline Yes & 85 & $54(63.5)$ & $13(15.3)$ & $79(92.9)$ & $58(68.2)$ & $78(91.7)$ & $42(49.4)$ & $76(89.4)$ \\
\hline P & & 0.277 & 0.248 & 0.385 & 0.585 & 0.359 & 0.716 & 0.222 \\
\hline \multicolumn{9}{|l|}{ Alcohol } \\
\hline Nonconsumer & 253 & $170(67.2)$ & $47(18.2)$ & $225(88.9)$ & $157(62)$ & $226(89.3)$ & $141(55.7)$ & $231(91.3)$ \\
\hline Consumer & 301 & $205(68.1)$ & $72(23.9)$ & $274(91)$ & $192(63.8)$ & $276(91.7)$ & $153(50.8)$ & $270(89.7)$ \\
\hline Ex-consumer & 48 & $38(79.2)$ & $11(22.9)$ & $40(83.3)$ & $32(66)$ & $40(83.3)$ & $24(50)$ & $40(83.3)$ \\
\hline$P$ & & 0.252 & 0.725 & 0.497 & 0.121 & 0.128 & 0.768 & 0.502 \\
\hline \multicolumn{9}{|l|}{ Heavy alcohol } \\
\hline No & 534 & $366(68.5)$ & $102(19.1)$ & $478(89.5)$ & $335(62.7)$ & $479(89.7)$ & $286(53.6)$ & $480(89.9)$ \\
\hline yes & 68 & $47(69.1)$ & $18(26.5)$ & $61(89.7)$ & $46(67.6)$ & $63(92.6)$ & $32(47)$ & $61(89.7)$ \\
\hline$P$ & & 0.923 & 0.152 & 0.867 & 0.662 & 0.716 & 0.489 & 0.774 \\
\hline
\end{tabular}


TABle 1: Continued.

\begin{tabular}{|c|c|c|c|c|c|c|c|c|}
\hline Variables & $n$ & $\begin{array}{c}\text { Oral cancer } \\
\text { awareness } \\
(n=413 ; \\
68.6 \%)\end{array}$ & $\begin{array}{c}\text { Oral cancer } \\
\text { screening } \\
(n=120 \\
19.9 \%)\end{array}$ & $\begin{array}{c}\text { Tobacco as } \\
\text { risk factor } \\
(n=539 ; \\
89.5 \%)\end{array}$ & $\begin{array}{c}\text { Alcohol as } \\
\text { risk factor } \\
(n=381 ; \\
63.2 \%)\end{array}$ & $\begin{array}{l}\text { Ulcer as sign } \\
\qquad \begin{array}{c}n=542 ; \\
90 \%)\end{array}\end{array}$ & $\begin{array}{c}\text { Red/white } \\
\text { patch as sign } \\
(n=318 ; \\
52.8 \%)\end{array}$ & $\begin{array}{c}\text { Swelling as } \\
\text { sign } \\
(n=541 ; \\
89.9 \%)\end{array}$ \\
\hline \multicolumn{9}{|c|}{ Fruit and vegetables } \\
\hline$<5$ units/day & 459 & $322(70.2)$ & $91(19.8)$ & $406(88.5)$ & $283(61.7)$ & $410(89.3)$ & $242(52.7)$ & $412(89.7)$ \\
\hline$\geq 5$ units/day & 143 & $91(63.6)$ & $29(20.2)$ & $133(93)$ & $98(68.5)$ & $132(92.3)$ & $76(53.1)$ & $129(90.2)$ \\
\hline$P$ & & 0.143 & 0.906 & 0.173 & 0.235 & 0.531 & 0.621 & 0.892 \\
\hline \multicolumn{9}{|c|}{ Oral hygiene frequency } \\
\hline$<1$ per day & 70 & $38(54.3)$ & $15(21.4)$ & $63(90)$ & $42(60)$ & $55(78.6)$ & $31(44.2)$ & $56(80)$ \\
\hline$\geq 1$ per day & 532 & $375(70.5)$ & $105(19.7)$ & $476(89.4)$ & $339(63.7)$ & $487(91.5)$ & $287(53.1)$ & $485(91.2)$ \\
\hline$P$ & & 0.006 & 0.739 & 0.957 & 0.831 & 0.001 & 0.296 & 0.012 \\
\hline \multicolumn{9}{|l|}{ Dentist visits } \\
\hline$<1$ year & 339 & $218(64.3)$ & $60(17.7)$ & $300(88.6)$ & $204(60.2)$ & $299(88.2)$ & $172(50.7)$ & $299(88.2)$ \\
\hline$\geq 1$ per year & 263 & $195(74.1)$ & $60(22.8)$ & $239(90.9)$ & $177(67.3)$ & $243(92.4)$ & $146(55.5)$ & $242(92)$ \\
\hline$P$ & & 0.019 & 0.119 & 0.465 & 0.149 & 0.043 & 0.231 & 0.234 \\
\hline
\end{tabular}

TABLE 2: Most mentioned cancers in the survey.

\begin{tabular}{lcc}
\hline Type of cancer & $(n)$ & $(\%)$ \\
\hline Breast & 596 & 99 \\
Lung & 580 & 96.3 \\
Prostate & 574 & 95.2 \\
Stomach & 546 & 90.7 \\
Colon & 532 & 88.4 \\
Pancreas & 519 & 86.2 \\
Thyroid & 482 & 80.1 \\
Cervical & 477 & 79.2 \\
Skin & 474 & 78.7 \\
Mouth & 413 & 68.6 \\
\hline
\end{tabular}

Only $86(14.3 \%)$ subjects cited oral cancer mortality to be around 50\%. Two hundred and thirty-one individuals (38.4\%) referred a mortality lower than $25 \%$ and 117 (19.4\%) above 75\%. The remaining 168 (27.9\%) could not respond to this question.

In relation to the causes of oral cancer, $539(89.5 \%)$ individuals identified tobacco and 381 (63.3\%) alcohol as a cause of oral cancer. It is curious to note that $194(32.3 \%)$ individuals considered oral cancer was caused by dental treatment at the dental office and another 118 (19.6\%) replied it was caused by close contact with other cancer patients (Table 3 ).

Patients with smoking habits identified tobacco as a cause of oral cancer $(95.7 \%)$ more frequently than the nonsmokers (86.9\%) $(P=0.048)$. Further significant findings were noted in relation to other demographic factors of the sample and their knowledge on risk factors, but the clinical relevance of these findings is obscure (Table 1).

Ninety percent $(n=542)$ of the individuals were able to identify "an ulcer that does not heal" and 541 (89.9\%) a "lump/tissue that overgrows" as signs of oral cancer (Table 4). However, only 318 (52.8\%) identified a white or
TABLE 3: Most risk factors or causes mentioned for oral cancer.

\begin{tabular}{lcc}
\hline Causes of cancer & $(n)$ & $(\%)$ \\
\hline Tobacco & 539 & 89.5 \\
Reduced oral hygiene & 501 & 83.2 \\
Infections in the teeth & 492 & 81.7 \\
Alcohol & 381 & 63.3 \\
Reduced intake fruit and vegetables & 295 & 49 \\
Sun exposure & 294 & 48.8 \\
Car smoke & 283 & 47 \\
Dental treatment in dentists & 194 & 32.2 \\
Coffee & 137 & 22.8 \\
Close contact with another cancer patient & 118 & 19.6 \\
\hline
\end{tabular}

TABLE 4: Mostly mentioned early manifestations of oral cancer.

\begin{tabular}{lcc}
\hline Signs and symptoms & $n$ & $\%$ \\
\hline Sore (ulcer) that does not heal & 542 & 90 \\
Lump or tissue overgrow & 541 & 89.9 \\
Difficulty in swallowing & 390 & 64.8 \\
Hemorrhage & 370 & 61.5 \\
Abscess, boil, or infection & 359 & 59.6 \\
Difficulty in open the mouth & 338 & 56.1 \\
Persistent white or red patch & 318 & 52.8 \\
Gastric pain & 250 & 41.5 \\
Prosthesis that fails to fit & 201 & 33.4 \\
Having aphthae very often & 163 & 27.1 \\
\hline
\end{tabular}

red spot or patch as a sign of oral cancer. The reference that "an ulcer that does not heal" could be a sign of oral cancer was correlated with frequent oral hygiene $(P=0.001)$, and frequency of dental visits $(P=0.043)$. The reference that "lump or tissue that overgrows" could be a sign of oral cancer was correlated with frequent oral hygiene $(P=0.012)$ and higher education level $(P<0.001)$ (Table 1$)$. 
TABLE 5: Socio-demographic characteristics and their relations with some cancer beliefs variables.

\begin{tabular}{|c|c|c|c|c|}
\hline & $n$ & $\begin{array}{c}\text { Disagree with } \\
\text { question of luck } \\
(n=364 ; 60.5 \%)\end{array}$ & $\begin{array}{l}\text { Early detection can } \\
\text { improve treatment } \\
(n=569 ; 94.5 \%)\end{array}$ & $\begin{array}{l}\text { Lifestyle influence } \\
\text { risk of oral cancer } \\
(n=495 ; 82.2 \%)\end{array}$ \\
\hline \multicolumn{5}{|l|}{ Gender } \\
\hline Male & 221 & $134(60.6)$ & $211(100)$ & $187(84.6)$ \\
\hline Female & 381 & $230(60.4)$ & $358(94)$ & $308(80.8)$ \\
\hline$P$ & & 0.949 & 0.432 & 0.243 \\
\hline \multicolumn{5}{|l|}{ Age } \\
\hline$<49$ years & 298 & $216(72.5)$ & $284(95.3)$ & $262(87.9)$ \\
\hline$>49$ years & 304 & $148(48.7)$ & 285 (93.7) & $233(76.6)$ \\
\hline$P$ & & $<0.001$ & 0.403 & $<0.001$ \\
\hline \multicolumn{5}{|l|}{ Professional class } \\
\hline $\mathrm{I} / \mathrm{II}$ & 56 & $46(82.1)$ & $53(94.6)$ & $50(89.2)$ \\
\hline III & 51 & $34(66.6)$ & $49(96)$ & $45(88.2)$ \\
\hline IV & 188 & $115(61.1)$ & $175(93)$ & $157(83.5)$ \\
\hline $\mathrm{V}$ & 307 & $169(55)$ & $292(95.1)$ & $243(79.1)$ \\
\hline$P$ & & 0.001 & 0.754 & 0.147 \\
\hline \multicolumn{5}{|l|}{ Marital status } \\
\hline Single & 112 & $85(75.8)$ & $110(98.2)$ & $99(88.4)$ \\
\hline Married & 402 & $233(57.9)$ & $381(94.8)$ & $328(81.6)$ \\
\hline Widow/divorced/separated & 88 & $46(52.3)$ & $78(88.6)$ & $68(77.3)$ \\
\hline$P$ & & 0.001 & 0.012 & 0.105 \\
\hline \multicolumn{5}{|l|}{ Education } \\
\hline Without & 50 & $21(42)$ & $45(90)$ & $34(68)$ \\
\hline Primary school & 429 & $236(55)$ & $404(94.1)$ & $348(81.1)$ \\
\hline Secondary & 81 & $69(85.2)$ & $79(97.5)$ & $73(90.1)$ \\
\hline Technic-vocation/university & 42 & $38(90.5)$ & $41(97.6)$ & $40(95.2)$ \\
\hline$P$ & & $<0.001$ & 0.234 & 0.001 \\
\hline \multicolumn{5}{|l|}{ Smoking } \\
\hline Nonsmoker & 367 & $214(58.3)$ & $345(94)$ & $297(80.9)$ \\
\hline Smoker & 141 & $97(68.8)$ & $135(95.7)$ & $123(87.2)$ \\
\hline Ex-smoker & 94 & $53(56.4)$ & $89(94.7)$ & $75(79.8)$ \\
\hline$P$ & & 0.065 & 0.741 & 0.199 \\
\hline \multicolumn{5}{|l|}{ Heavy smoking } \\
\hline No & 517 & $313(60.5)$ & $489(94.6)$ & $426(82.4)$ \\
\hline Yes & 85 & $51(60)$ & $80(94.1)$ & $69(81.1)$ \\
\hline$P$ & & 0.925 & 0.861 & 0.761 \\
\hline \multicolumn{5}{|l|}{ Alcohol } \\
\hline Nonconsumer & 253 & $157(62)$ & $232(91.7)$ & $200(79)$ \\
\hline Consumer & 301 & $186(61.8)$ & $290(96.3)$ & $255(84.7)$ \\
\hline Ex-consumer & 48 & $21(43.8)$ & $47(97.9)$ & $40(83.3)$ \\
\hline$P$ & & 0.047 & 0.032 & 0.216 \\
\hline \multicolumn{5}{|l|}{ Heavy alcohol } \\
\hline No & 534 & $331(61.9)$ & $503(94.1)$ & $436(81.6)$ \\
\hline yes & 68 & $33(48.5)$ & $66(97)$ & $59(86.8)$ \\
\hline$P$ & & 0.033 & 0.328 & 0.299 \\
\hline
\end{tabular}


TABle 5: Continued.

\begin{tabular}{|c|c|c|c|c|}
\hline & $n$ & $\begin{array}{c}\text { Disagree with } \\
\text { question of luck } \\
(n=364 ; 60.5 \%)\end{array}$ & $\begin{array}{c}\text { Early detection can } \\
\text { improve treatment } \\
(n=569 ; 94.5 \%)\end{array}$ & $\begin{array}{l}\text { Lifestyle influence } \\
\text { risk of oral cancer } \\
(n=495 ; 82.2 \%)\end{array}$ \\
\hline \multicolumn{5}{|l|}{ Fruit and vegetables } \\
\hline$<5$ units/day & 459 & $281(61.2)$ & $431(93.9)$ & $375(81.7)$ \\
\hline$>5$ units/day & 143 & $83(58)$ & $138(96.5)$ & $120(83.9)$ \\
\hline$P$ & & 0.497 & 0.232 & 0.545 \\
\hline \multicolumn{5}{|l|}{ Oral hygiene frequency } \\
\hline$<1$ day & 70 & $25(35.7)$ & $57(81.4)$ & $56(80)$ \\
\hline 1 or more per day & 532 & $339(63.7)$ & $512(96.2)$ & $439(82.5)$ \\
\hline$P$ & & $<0.001$ & $<0.001$ & 0.604 \\
\hline \multicolumn{5}{|l|}{ Dentist visits } \\
\hline$<1$ year & 339 & $181(53.3)$ & 315 (92.9) & $277(81.7)$ \\
\hline 1 or more per year & 263 & $183(69.6)$ & $254(96.6)$ & $218(82.9)$ \\
\hline$P$ & & $<0.001$ & 0.051 & 0.707 \\
\hline
\end{tabular}

Sixty-one percent ( $n=364$ ) of the subjects disagreed with the affirmation that "having oral cancer is a question of luck and there is nothing we can do to avoid it." However, 169 (28.1\%) agreed with this affirmation and 69 (11.5\%) could not form an opinion on this. Disagreement was associated with younger age $(P<0.001)$, single marital status $(P=$ $0.001)$, high professional class $(P=0.001)$, high education level $(P<0.001)$, lower alcohol consumption $(P=0.033)$, frequent oral hygiene $(P<0.001)$, and frequent dentist visits $(P<0.001)$ (Table 5).

Most subjects ( $n=569 ; 94.5 \%)$ agreed that the detection of oral cancer in early stages could increase the success of the treatment. This was rejected by 12 subjects $(1.9 \%)$, and $21(3.5 \%)$ were unable to respond. Married marital status $(P=0.012)$, history of alcohol consumption $(P=0.032)$, and frequent oral hygiene $(P<0.001)$ were significantly related to agreeing to this answer (Table 5).

Finally, when we asked the subjects if they agree that "we can change our lifestyle to reduce the risk of cancer of the mouth," 495 (82.2\%) said yes, 40 (6.6\%) disagreed with the affirmation, and $67(11.1 \%)$ could not form an opinion. Positive answers were associated with younger age $(P<$ $0.001)$ and higher education level $(P=0.001)$ (Table 5).

\section{Discussion}

Valongo is a northern Portuguese municipality with 93,573 inhabitants consisting of five local administrative units including Valongo, Ermesinde, Alfena, Sobrado, and Campo. It has one public district hospital that receives all citizens of Valongo. Almost every patient invited to this survey had accepted to participate (95.4\%) thus limiting any bias in generalizing our findings to other patients attending this hospital. The predominance of female individuals in the survey (60\%) is in accordance with other reports [7] and may be explained by random variation or by the fact that there is a greater proportion of women attending hospitals.
The oral cancer awareness and knowledge in the present population is poor. It is curious to note that oral cancer was the least mentioned of all cancers (68\%), even less than pancreatic cancer that has a lower incidence comparing to oral cancer. Our results are in line with the reports by Cruz et al. [10] in USA with an awareness of $66 \%$, lower than that reported by Ariyawardena and Vithanaarachchi [11] (awareness of 95\%) and West et al. [12] (awareness of 96\%) but a slightly higher than Prayman et al. [7] and Warnakulasuriya et al. [6] with an awareness of $55 \%$ and $56 \%$, respectively. These data come from various populations researched over a decade or so.

That smoking is a risk factor for oral cancer was realized by the majority of the subjects. However, alcohol was identified to a lesser degree as a risk factor. This trend was also reported by others $[6,7,10,13-15]$. It may be related to general health campaigns that primarily promoted tobacco cessation. This groups' awareness on alcohol as a risk factor was lower to the observed figures by Palencia et al. [16]. A recent retrospective study conducted in a head and neck unit in Lisbon, Portugal, reported consumption of alcohol to be the major risk factor for tongue cancer in their cohort of cancer patients [17]. For Portugal, strengthening people knowledge on their increased cancer risks by alcohol use should be included in future health promotion strategies.

Although the presence of a nonhealing wound and oral lumps was widely identified as one of the first signs of oral cancer, the presence of white or red persistent plaques was not associated with oral cancer by almost half of the individuals. This is in accordance with other reports $[12,13]$. This can be problematic because in addition to being an early sign of cancer they can correspond to potentially malignant disorders whose elimination in time could contribute to reducing the risk of developing mouth cancer.

A disheartening $98.5 \%$ of the individuals were never submitted to a consultation or had knowledge of been screened for oral cancer. Comparing with other reports this 
result is one of the lowest published in scientific literature $[10,15,18]$. This is a drawback in our healthcare system that needs to be strengthened in Portugal. Educational campaigns at the population level should be established to transmit accurate information and motivation towards oral cancer prevention. The design of oral cancer screening campaigns properly calibrated becomes urgent, especially among the individuals with high risk for oral cancer. Opportunistic oral cancer screening examination undertaken when patients attend a healthcare professional specially a dentist may be important in this view. However, they must be complemented with other primary care activities because, as we observed in our work, many subjects did not go to the dentist regularly. A network of private and public dentists, and other healthcare professional at health centers or hospitals including GP, nurses, would form an ideal oral cancer screening team providing access for everyone. Primary healthcare professionals can contribute to efficient oral cancer screening [19]. Moreover, this should be complemented with active campaigns of awareness and knowledge on oral cancer by health institutes or the government. Recently, at the end of this study, our service in association with the Valongo municipality administration held an oral cancer screening day for the population of Valongo, an initiative very encouraging and that should serve as an example for other similar activities.

A recent population-based survey of adults in the UK has shown that a combination of public education of symptoms and empowerment to seek medical advice, as well as support at the primary care level, could enhance early presentation and improve cancer outcomes [20]. A systematic review has reported some evidence that interventions delivered at individual or community level may increase cancer awareness [21]. However, whether awareness leads to early presentation of oral cancer is being debated, and evidence is somewhat limited [22]. Early diagnosis and rapid access for treatment of cancer is an important factor for improving outcomes for oral cancer. Programs such as awareness campaigns and population screenings remain important public health measures to reduce delays in diagnosis.

In the present work, although most of the subjects agree that the detection of oral cancer in early stages can increase the success of the treatment, approximately onethird believed that whether a person developed an oral cancer or not was a matter of luck and therefore was unavoidable. This may be associated to a fatalism concept also observed by Warnakulasuriya et al. [6]. Fatalism attitude to health might be a critical obstacle to changing lifestyles and may be responsible in people either not accepting professional advice on avenues for prevention or arriving too late for the therapy. Associations of this fatalism with old age, poor education and professional class, and heavy alcohol consumption were evident in the present work. Education of the public, particularly young people, may help to change the common attitude that cancer affliction is a matter of chance.

A limitation of our study that we would like to acknowledge is that we surveyed a hospital population attending outpatient clinics. It would have been ideal to survey a random sample of the general population, but our resources were limited. We therefore would caution generalizing the findings of this survey to Portuguese people.

\section{Conclusion}

This survey highlights the general lack of awareness and knowledge on oral cancer among a population of Valongo. Almost all individuals had never been submitted to oral cancer screening nor had knowledge of been examined for case detection. An oral health promotion strategy should involve elements of basic education on oral cancer as well oral cancer screening that should be implemented for this population.

\section{Conflict of Interests}

The authors declare that there are no conflicts of interest.

\section{References}

[1] S. Warnakulasuriya, "Global epidemiology of oral and oropharyngeal cancer," Oral Oncology, vol. 45, no. 4-5, pp. 309-316, 2009.

[2] J. Ferlay, H. R. Shin, F. Bray, D. Forman, C. Mathers, and D. M. Parkin, "GLOBOCAN 2008: Cancer Incidence and Mortality Worldwide," IARC CancerBase 10, International Agency for Research on Cancer, Lyon, France, 2010.

[3] S. R. Moore, N. W. Johnson, A. M. Pierce, and D. F. Wilson, "The epidemiology of mouth cancer: a review of global incidence," Oral Diseases, vol. 6, no. 2, pp. 65-74, 2000.

[4] S. Warnakulasuriya, "Causes of oral cancer-an appraisal of controversies," British Dental Journal, vol. 207, no. 10, pp. 471475, 2009.

[5] B. W. Stewart and P. Kleihues, World Cancer Report, International Agency for Research on Cancer, Geneva, Switzerland, 2003.

[6] S. Warnakulasuriya, C. K. Harris, D. M. Scarrott et al., "An alarming lack of public awareness towards oral cancer," British Dental Journal, vol. 187, no. 6, pp. 319-322, 1999.

[7] E. Prayman, Y. Yang, and S. Wamakulasuriya, "Oral cancer awareness of patients attending health centres in Trinidad," International Journal of Clinical Dentistry, vol. 2, no. 4, pp. 1$12,2009$.

[8] Department of health (UK), Sensible Drinking: Report of an Inter-Departmental Working Group, London, UK, 1995.

[9] World Health Organization, "Diet, nutrition and the prevention of chronic diseases," WHO Technical Report Series 916, World Health Organization, Geneva, Switzerland.

[10] G. D. Cruz, R. Z. Le Geros, J. S. Ostroff, J. L. Hay, H. Kenigsberg, and D. M. Franklin, "Oral cancer knowledge, risk factors and characteristics of subjects in a large oral cancer screening program," Journal of the American Dental Association, vol. 133, no. 8, pp. 1064-1071, 2002.

[11] A. Ariyawardana and N. Vithanaarachchi, "Awareness of oral cancer and precancer among patients attending a hospital in Sri Lanka," Asian Pacific Journal of Cancer Prevention, vol. 6, no. 1, pp. 58-61, 2005.

[12] R. West, M. N. Alkhatib, A. McNeill, and R. Bedi, "Awareness of mouth cancer in Great Britain," British Dental Journal, vol. 200, no. 3, pp. 167-169, 2006.

[13] A. Pakfetrat, F. Falaki, H. O. Esmaily, and S. Shabestari, "Oral cancer knowledge among patients referred to Mashhad Dental 
School, Iran," Archives of Iranian Medicine, vol. 13, no. 6, pp. 543-548, 2010.

[14] S. N. Rogers, R. Hunter, and D. Lowe, "Awareness of oral cancer in the Mersey region," British Journal of Oral and Maxillofacial Surgery, vol. 49, no. 3, pp. 176-181, 2011.

[15] A. M. Horowitz, P. Nourjah, and H. C. Gift, "U.S. adult knowledge of risk factors and signs of oral cancers: 1990," The Journal of the American Dental Association, vol. 126, no. 1, pp. 39-45, 1995.

[16] M. R. R. Palencia, M. A. B. González, Y. C. Alonso et al., "Knowledge and attitudes related with cancer prevention in a population served at a health center," Atencion Primaria, vol. 18, no. 8, pp. 417-424, 1996.

[17] R. P. Albuquerque, J. Lopez-Lopez, E. Jane-Salas, J. RosaSantos, and C. Ibrahim, "A pioneering epidemiological study investigating the incidence of squamous cell carcinoma of tongue in a Portuguese population," Medicina Oral, Patologia Oral Y Cirurgia Bucal, vol. 17, no. 4, pp. e550-e554, 2012.

[18] S. L. Tomar and H. L. Logan, "Florida adults' oral cancer knowledge and examination experiences," Journal of Public Health Dentistry, vol. 65, no. 4, pp. 221-230, 2005.

[19] S. Warnakulasuriya, A. N. I. Ekanayake, S. Sivayoham et al., "Utilization of primary health care workers for early detection of oral cancer and precancer cases in Sri Lanka," Bulletin of the World Health Organization, vol. 62, no. 2, pp. 243-250, 1984.

[20] K. Robb, S. Stubbings, A. Ramirez et al., "Public awareness of cancer in Britain: a population-based survey of adults," British Journal of Cancer, vol. 101, no. 2, pp. S18-S23, 2009.

[21] J. Austoker, C. Bankhead, L. J. Forbes et al., "Interventions to promote cancer awareness and early presentation: systematic review," British Journal of Cancer, vol. 101, no. 2, pp. S31-S39, 2009.

[22] E. Grant, K. Silver, L. Bauld, R. Day, and S. Warnakulasuriya, "The experiences of young oral cancer patients in Scotland: symptom recognition and delays in seeking professional help," British Dental Journal, vol. 208, no. 10, pp. 465-471, 2010. 


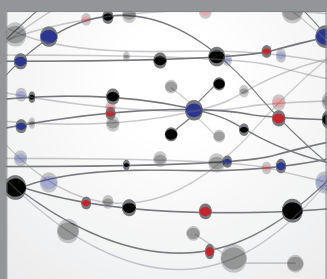

The Scientific World Journal
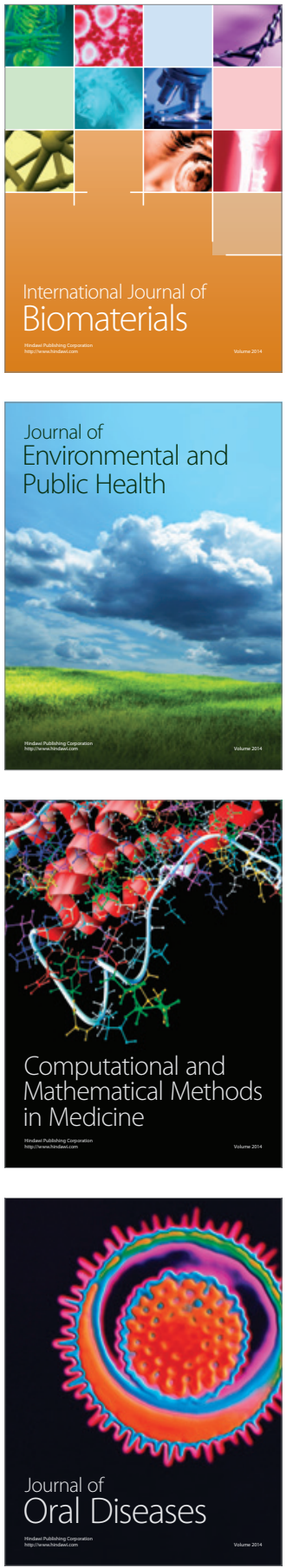
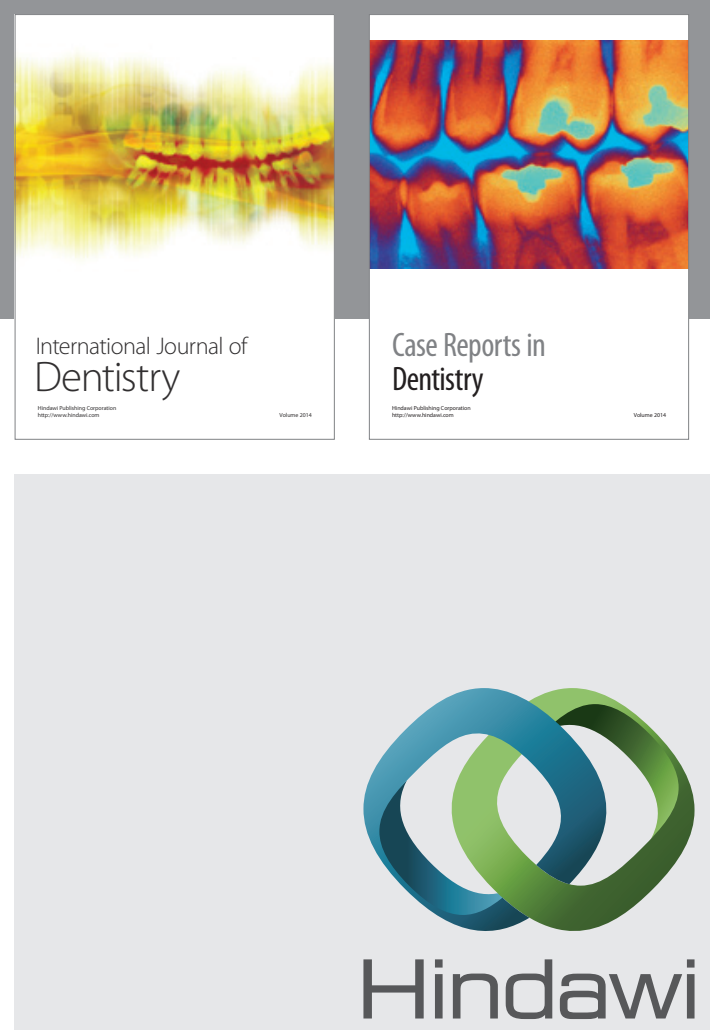

Submit your manuscripts at

http://www.hindawi.com
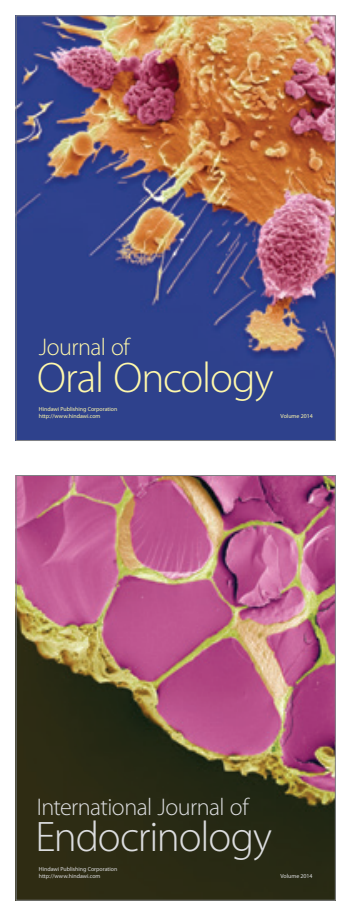
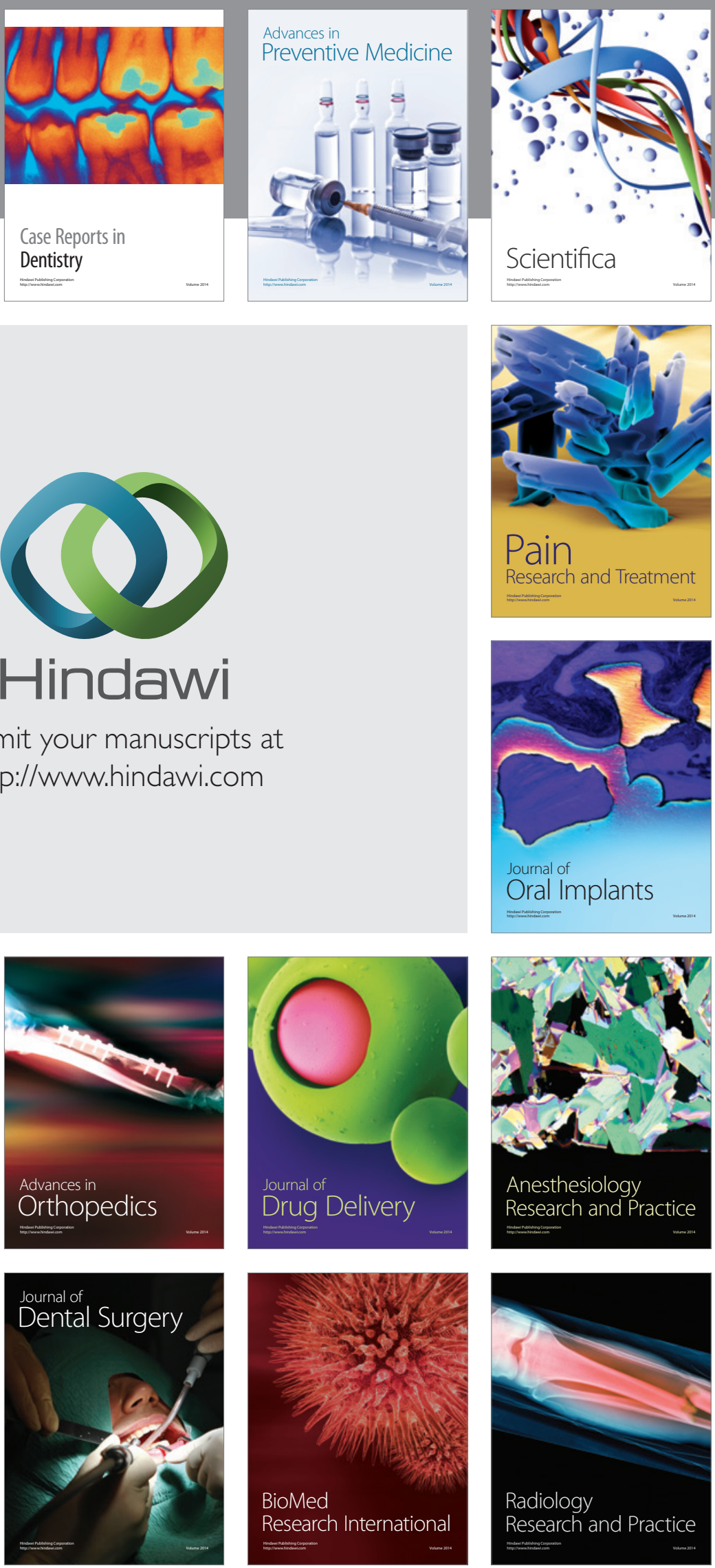